\title{
Investigation on Performance of Shell and Tube Heat Exchanger with Assorted Baffle Parameters
}

\author{
Levicus John ${ }^{1}$, Khasim Sharif $\mathrm{Sk}^{2,}$ D.Jagadish ${ }^{3}$, K. Phaneendra Kumar ${ }^{4}$ \\ ${ }^{1}$ (Assistant professor, Mechanical Department, CMRTC/ JNTUH, India) \\ ${ }_{2}^{2}$ (Assistant professor Mechanical Department, CMRTC/ JNTUH, India) \\ ${ }^{3}$ (professor, Mechanical Department, VFSTR, India) \\ ${ }^{4}$ (professor\& principal, Mechanical Department, VLITS, India)
}

\begin{abstract}
Shell and Tube heat exchangers (STHXs) are extensively used in the ever growing process industry requirements. With the advancement in the technology used in the STHXs we have seen a tremendous use of the helical baffles to improve the heat transfer performance. From varying angles to sizes and shapes of the helical baffles our priority is mainly to compare and study the performance improvements from segmental baffles to helical baffles. In this paper an experimental setup has been made for both Shell and Tube heat exchangers with segmental baffles (STHXsSB) and Shell and Tube Heat exchangers with Helical Baffles (STHXsHB). The helical baffles used here are discontinuous-helical baffles. The widely used Bell-Delaware method is used to validate the experimental data.
\end{abstract}

Keywords: Baffles, Blade Angle, Heat exchanger, helical baffles, pressure drop

\section{Introduction}

Ever since the industrial revolution in the Eighteenth century we have been ultimately dependent on Energy. Energy however comes in various forms broadly classified as high grade energy and low grade energy, high grade energy being Electricity and the low grade energy being other various forms of energy such as Heat energy. Low grade energy may be available to us and it is our responsibility to utilize it efficiently especially when energy sources are being depleted at a very high rate on this planet. Every bit of energy which is being wasted is without doubt useful to us. Keeping this in mind we see an important study in heat exchangers which deals with low grade energy that is heat energy or in other words Thermal energy[1]. Thermal energy loss in the process industry is a significant issue due to the high temperatures and multiple heat intensive processes involved. High-grade thermal energy is typically recovered within processes. However, lower grade heat is often rejected to the environment. The benefits of capturing and utilizing low grade thermal energy are highly dependent on the qualities and properties of the heat in the waste streams. The temperature of the low grade heat stream is the most important parameter, as the effective use of the residual heat or the efficiency of energy recovery from the low grade heat sources will mainly depend on the temperature difference between the source and a suitable sink [2].

\subsection{HEAT EXCHANGERS}

A heat exchanger is a device used to transfer heat between two or more fluids. The fluids can be single or two phase and, depending on the exchanger type, may be separated or in direct contact. Devices involving energy sources such as nuclear fuel pins or fired heaters are not normally regarded as heat exchangers although many of the principles involved in their design are the same.

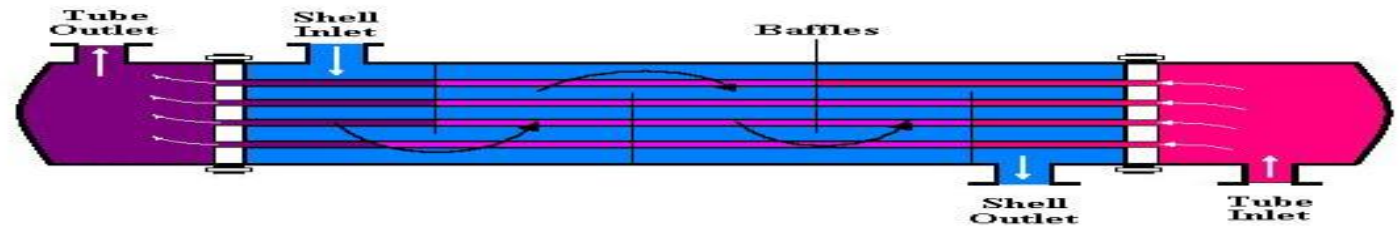

Figure-1.Heat exchanger

- Front end-this is where the fluid enters the tube side of the exchanger.

- Rear end-this is where the tube side fluid leaves the exchanger or where it is returned to the front header in exchangers with multiple tube side passes.

- Tube bundle-this comprises of the tubes, tube sheets, baffles and tie rods etc. to hold the bundle together.

- Shell-this contains the tube bundle. 
The popularity of shell and tube exchangers has resulted in a standard being developed for their designation and use [3]. This is the Tubular Exchanger Manufactures Association (TEMA) Standard. In general shell and tube exchangers are made of metal but for specialist applications (e.g., involving strong acids of pharmaceuticals) other materials such as graphite, plastic and glass may be used. It is also normal for the tubes to be straight but in some cryogenic applications helical or Hampson coils are used [4].

\subsection{DESIRABLE FEATURES OF HEAT EXCHANGERS}

In order to obtain maximum heat exchanger performance at the lowest possible operating and capital costs without compromising reliability, the following features are required of an exchange.

a) Higher heat transfer coefficient and larger heat transfer area. These two factors increase the heat transfer rate for a given temperature difference and therefore improve the heat exchanger effectiveness or temperature approach. A high heat transfer coefficient can be obtained by using heat transfer surfaces which promote local turbulence for single-phase flow or have some special features for two-phase flow. Heat transfer area can be increased by using larger exchangers, but the more cost-effective way is to use a heat exchanger having a large area density per unit exchanger volume. For some duties, such as those involving a gaseous phase, secondary heat transfer area is also very useful. High area densities become economically even more attractive when an exchange is built from expensive special materials such as titanium or nickel.

b) Lower pressure drop. Pumping costs are dependent on pressure drop within an exchange. Therefore lower pressure drop means lower operating costs. Normally the devices or surfaces that provide high heat transfer coefficients also give high pressure gradients, i.e., pressure drop per unit length of flow path. Exchangers designed to give enhanced performance, however, require shorter flow paths to achieve a given duty. It is therefore possible that these exchangers have a high pressure gradient but not so high a pressure drop.

c) Counter current flow arrangement. In order to obtain maximum mean temperature driving difference, a pure counter current flow arrangement is desirable. Any deviation from this arrangement reduces the mean temperature driving difference, and a correction factor to the log-mean temperature difference needs to be applied. Most of the compact heat exchangers can be configured to provide pure counter current flow.

\subsection{BAFFLES}

Baffles are flow-directing or obstructing vanes or panels used in some industrial process vessels (tanks), such as shell and tube heat exchangers, chemical reactors, and static mixers. Baffles are an integral part of the shell and tube heat exchanger design. A baffle is designed to support tube bundles and direct the flow of fluids for maximum efficiency.

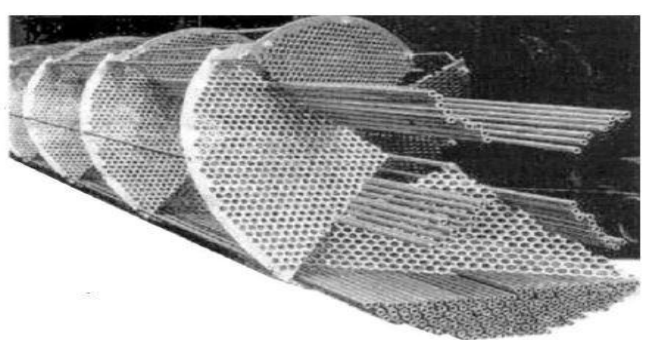

Figure- 2. Baffles

\subsection{HELICAL-BAFFLE EXCHANGER}

A number of developments in shell-and-tube exchanger design have taken place which addresses these issues [1]. As an example of these developments, the helical-baffle exchanger is discussed first in detail. This is then followed by a discussion of other important developments. A shell-and-tube exchanger using a helical baffle was developed in the Czech Republic [2-4]. A similar exchanger was also developed independently by a Norwegian group [5]. This exchanger, also known as a Helix changer, minimizes the principal shortcomings of the conventional segmental baffle design. The principle of Helix changer.

Design is quite simple and circular sector-shaped plates are arranged in a pseudo-helical baffle system. Each baffle occupies one quadrant of the exchanger shell cross section and is angled to the axis of the heat exchanger [6]. Adjacent baffles may touch at the perimeter, forming a continuous helix at the outer periphery. Axial overlapping of baffles may be used, or a double-helix design may be employed. The last arrangement is important when unsupported tube spans need to be reduced. 


\section{Objectives And Problem Statement}

Heat transfer Phenomenon can be studied by both experimental methods and analytical methods. Here both the methods are used and each one in validated with each other. The dimensions and specifications of the heat exchangers influence the heat transfer capacity and also the pressure drop. There may be significant changes in the answers from analytical and experimental methods due to the influence of real time situations and friction factors involved in experimental setup. Pressure drop values can also be found in this setup as it is a major factor in the performance of the heat exchangers.However, the principal shortcomings of the conventional segmental baffle still remains in the improved structures of the abovementioned studies. A new type of baffle, called the helical baffle, provides further improvement Lutcha et al [12] they first developed this type of baffle. They investigated the flow field patterns produced by such helical baffle geometry with different helix angles. They found that these flow patterns were very close to the plug flow condition, which was expected to reduce shell-side pressure drop and to improve heat transfer performance Stehlik et al. [13] compared heat transfer and pressure drop correction factors for a heat exchanger with an optimized segmental baffle based on the Bell-Delaware method [2-4] with those for a heat exchanger with helical baffles.

\subsection{PARTICULARS ABOUT THE HELICAL BAFFLES}

For the convenience of manufacturing, up to now all helical baffles actually used in STHXs are noncontiguous approximate helicoids. The noncontiguous helical baffles are usually made by four elliptical sector-shaped plates joined in succession. The elliptical sector-shaped plates are arranged in a pseudo helical (noncontinuous) manner, with each baffle occupying one-quarter of the cross section of the heat exchanger and being angled to the axis of the heat exchanger. The two adjacent baffles may be joined end to end at the perimeter of each sector forming a continuous helix at the outer periphery this structure of connecting baffles together is called a single helix manner. Another connection between two adjacent sectors is the middle-overlapped connection.

2.1.1. Correlations for Heat Transfer Coefficient in Shell Side of STHsHB.

The average Nu number for the shell side of STHXsHB is determined by

$\mathrm{Nu}_{s}=0.62 \times\left(0.3+\sqrt{\mathrm{Nu}_{\mathrm{lam}}^{2}+\mathrm{Nu}_{\text {turb }}^{2}}\right) \times \mathrm{Y}_{2} \times \mathrm{Y}_{3} \times \mathrm{Y}_{4} \times \mathrm{Y}_{7} \times \mathrm{Y}_{8} \times \mathrm{Y}_{9} \times \mathrm{Y}_{10}$

Where, $N u_{\text {lam }}=0.664 \operatorname{Re}^{0.5} \operatorname{Pr}^{0.33}$

$$
N u_{\text {turb }}=\frac{0.037 \operatorname{Re}^{0.7} \mathrm{Pr}}{1+2.433 \operatorname{Re}^{-0.1}\left(\mathrm{Pr}^{0.67}-1\right)}
$$

In Eq. 1 coefficients $Y i$ are the correction factors. Their physical meanings are defined as follows [13]. Y2 accounts for the thermal-physics properties effects; $Y 3$ accounts for the scale-up from a single tube row to a bundle of tubes; $Y 4$ accounts for the adverse temperature gradient; $Y 7$ accounts for the bundle-shell bypass streams; $Y 8$ accounts for the baffle spacing in inlet and outlet sections; $Y 9$ accounts for the change in the crossflow characteristics in heat exchanger; and $Y 10$ accounts for the turbulent enhancement.

Average heat transfer coefficient for shell side of STHXsHB is

$$
\begin{aligned}
\mathrm{h}_{\mathrm{s}} & =\frac{N u_{s} \times \lambda_{s}}{l} . \\
& =\frac{\pi \mathrm{d}_{\mathrm{o}}}{2} \ldots \ldots \ldots . .
\end{aligned}
$$

Where,

Where $d_{o}$ is the outside diameter of the tube; and $\lambda_{s}$ is thermal conductivity of shell-side fluid. The application ranges of Eqs. (1) - (5) are $10<\operatorname{Re}<10^{6}, 10<\operatorname{Pr}<10^{3}, n_{r c}>10,5 \leq \beta \leq 45 \mathrm{deg}$, where

$$
n_{r c}=n_{r p}\left(n_{p}-1\right)
$$

\subsection{Correlations for Pressure Drop in Shell Side of STHXSHB.}

According to Stehlik et al. the pressure drop cross the bundle per unit cycle without bypass flow can be determined by

$$
\Delta p_{t 0}^{1}=2 \lambda_{22} n_{r}^{1} \rho_{2} u_{2}^{2} Z_{2} Z_{6} Z_{7}
$$

The pressure drop across the whole bundle zone with bypass flow is 


$$
\Delta p_{t 0}=\Delta p_{t 0}^{1} \frac{l_{t 0}}{B} Z_{3}
$$

The pressure drop in the inlet and outlet zones

$$
\Delta p_{t n}=\Delta p_{t 0}^{1} Z_{5}
$$

Where $n_{r}^{1}$ is the number of tube rows on the center stream line within one cycle, $\lambda_{22}$ is the friction factor of ideal cross-flow through tube bundle, which can be determined by referring to $[6,8] . l_{t 0}$ is the baffled length of tube bundle. In eqs. (7)-(9) correction factors are defined as [13] follows. $Z_{2}$ accounts for the thermal-physics properties effects; $Z_{3}$ accounts for the bundle-shell bypass streams; $Z_{5}$ accounts for the baffle spacing in inlet and outlet sections; $Z_{6}$ accounts for the change in the cross-flow characteristcs in heat exchanger; and $Z_{7}$ accounts for the turbulent enhancement.The pressure drop in the inlet and outlet nozzles can be calculated by[11,12]

$$
\Delta p_{\text {nozzle }}=\xi \times 0.5 \times \rho v_{s, \text { nozzle }}^{2}
$$

Where $\xi$ is taken as 1.5 or 2.0 by referring to Refs.[11,12].The over-all pressure drop of the shell-side fluid is

$$
\Delta p_{s, a l l}=\Delta p_{t n}+\Delta p_{\text {nozzle }}+\Delta p_{t 0}
$$

From above presentation it can be seen that the determination of factors and is the key issue to obtain the shellside fluid heat trasnfer coefficient and pressure drop. The section 2.3 is for this purpose.

2.3 Determination of factors. $Y_{2}$ and $Z_{2}[6,13]$.

$$
Y_{2}=\left(\frac{\eta_{s}}{\eta_{s_{s} W}}\right)^{0.14} \quad Z_{2}=\left(\frac{\eta_{s}}{\eta_{s_{s} W}}\right)^{-0.14}
$$

Where $\eta_{S_{i}, W}$ is the dynamic viscosity at average temperature of tube wall.

The determination of average temperature of tube wall is conducted by [6]

$$
t_{w}=t_{t_{i} \text { avg }}+\left(\frac{t_{s_{i} \text { avg }}-t_{t, \text { avg }}}{1+h_{t} / h_{s}}\right)
$$

$Y_{3}[13,14]$. For in-line arrangement,

$$
Y_{3}=1+\frac{0.7 b / a-0.3}{\varepsilon^{1.5}(b / a+0.7)^{2}}
$$

For staggered arrangement

$$
Y_{3}=1+\frac{2}{3 b}
$$

Where $a$ is the ratio of distance between the tube normal to the flow direction and the central tube pitch, $b$, is the ratio of distance between tube in the flow direction and the central tube pitch, as shown in Fig. 4, and the parameter $\varepsilon$ is determined $\mathrm{b}$

$$
\text { if } \quad b \geq 1: \quad \varepsilon=1-\frac{\pi}{4 a} ; \quad \text { if } \quad b<1: \quad \varepsilon=1-\frac{\pi}{4 a b}
$$

$Y_{7}$ and $Z_{3}[13] . Y_{7}$ and $Z_{3}$ are fucntions of $t_{t} \cdot n_{p t} / D_{1}$ and $S_{s s} / S_{2 z}$, as shown in graphs presented by Stehlik et al. [13]. These curved have been fitted to the following equations (using $x$ and $y$, respectively, to substitute $t_{t} \cdot n_{p t} / D_{1}$ and $S_{S S} / S_{2 z}$ for simplicity):

$$
\begin{gathered}
Y_{7}=\exp \left[-1.343 x\left(1-(2 y)^{0.338}\right)\right] \\
S_{s s}=0.5\left(B-S_{p} / \cos \beta\right)\left[D_{i}-D_{s}-S_{t t}\right] \\
S_{2 z}=0.5\left(B-S_{p} / \cos \beta\right)\left[D_{i}-D_{S}+\frac{D_{S}-d_{o}}{t_{t}}\left(t_{t}-d_{o}\right)\right]
\end{gathered}
$$

In the above equations, $t_{t}$ is the tube pitch, $D_{1}$ is the inner diameter of shell, $S_{p}$ is the thickness of baffle, $S_{t t}$ is distance between the two tubes' outside surfaces, $n_{p t}$ is the number of stealing strip pairs, and $D_{s}$ is the

$$
Z_{3}=\exp \left[-3.56 x\left(1-(2 y)^{0.363}\right)\right]
$$


Where, diameter of tube bundle. It should be emphasized that for the STHXsHB because the shell-side flow pattern resulted from the helical-type structure is close to helical flow, the cross section area, $S_{2 z}$, is actually only half of the entire cross section at the shell centerline of the heat exchanger.

$Y_{8}$ and $Z_{5}$ [13]. $Y_{8}$ and $Z_{5}$ are functions of $\left(l_{t c}-l_{t 0}\right) / l_{t c}$ and $B / D_{1}$, as shown in graphs presented by Stehlik et al. [13]. Again, the present authors have made curve-fitting for the convenience of design as follows (using $x$ and $y$, respectively, to substitute $\left(l_{t c}-l_{t 0}\right) / l_{t c}$ and $B / D_{1}$ for simplicity):

$$
\begin{gathered}
Y_{8}=1.079 y^{0.0487}-0.445 y^{-0.301} x^{1.2} \\
Z_{5}=(-0.0172+0.0899 y) x^{-1.2}
\end{gathered}
$$

Where $l_{t c}$ is the effective length of the tube bundle, and $l_{t 0}$ is the baffled length of tube bundle.Figure illustrates the definitions of $l_{t 0}$ and $l_{t c}$. The helical pitch $B$ can be calculated with $D_{1}$ and $\beta$ at hand. (see Eq. ()) [9], and then the maximum number of baffle numbers can be determined with specified value of $l_{t c}$. The baffle number is an integral. Then $l_{t 0}$ and the distances between inlet and outlet baffles to tube sheet, $l_{t n 1}$ and $l_{t n 2}$, can be determined with ease. $\quad B=\alpha n \cdot D_{1} \sin \frac{\pi}{n} \cdot \tan \beta, \quad n \geq 2, \quad 0<\alpha \leq 1$

Where $\alpha$ is the dimensionless radius of the contacting point of the two successive helical baffles (see Fig. $Y_{9}$ and $Z_{6}$ [13]. From the graphs presented by Stehlik et al. [13] $Y_{9}$ and $Z_{6}$ are only influenced by helical angle. The curves in [13] can be fitted to the following equations:

$$
\begin{gathered}
Y_{9}=0.977+0.00455 x-0.00001821 x^{2} \quad(18 \mathrm{deg} \leq x \leq 45 \mathrm{deg}) ; Y_{9}=1 \quad(x<18 \mathrm{deg}) \\
Y_{9}=0.289-\left(5.06 \times 10^{-4}\right) x-\left(4.53 \times 10^{-5}\right) x^{2}
\end{gathered}
$$

$Y_{10}$ and $_{7}$ [13]. $Y_{10}$ and $Z_{7}$ are also only influenced by the helical angle, as shown in the graphs presented by Stehlik et al. [13]. The following curve-fitted equations are obtained by the present authors:

$$
\begin{gathered}
Y_{10}=-56.39+8.28 x-0.46 x^{2}+0.012 x^{3}-\left(1.64 \times 10^{-4}\right) x^{4}+\left(8.19 \times 10^{-7}\right) x^{5} \\
(25 \mathrm{deg}<\mathrm{x}<45 \mathrm{deg}) ; Y_{10}=1 \quad(x<25 \mathrm{deg}) \\
Z_{7}=-5.411+0.379 x-0.00402 x^{2} \quad(2 \mathrm{deg}<x<45 \mathrm{deg}) \\
Z_{7}=1 \quad(x<22 \mathrm{deg}) \quad \text { Where } x \text { represents the helical angle } \beta .
\end{gathered}
$$

\subsection{Correlations for Pressure Drop in Tube Side of STHXsHB}

$$
\Delta p_{t, a l l}=\frac{1}{2} \xi \rho v_{t, \text { nozzle }}^{2}+\frac{1}{2} \rho u_{t}^{2}\left[\frac{f_{t} L_{t c}}{d_{i}} \frac{1}{\left(\phi_{t}\right)^{r}}+k_{c}+k_{e}+4\right] N_{p}
$$

\section{Modelling of Helical Baffle}

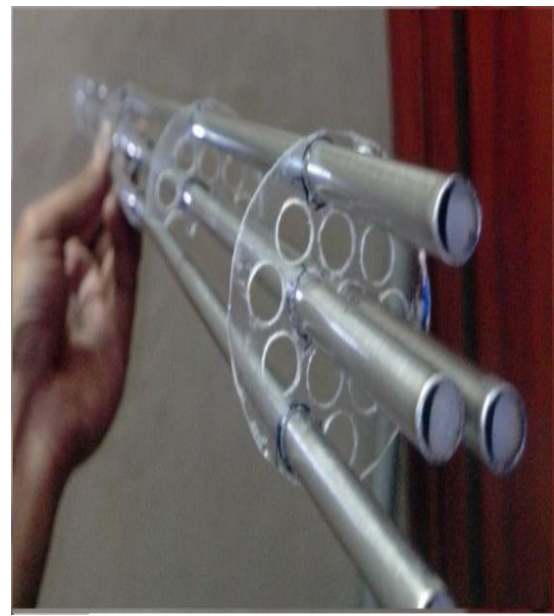

Figure-3

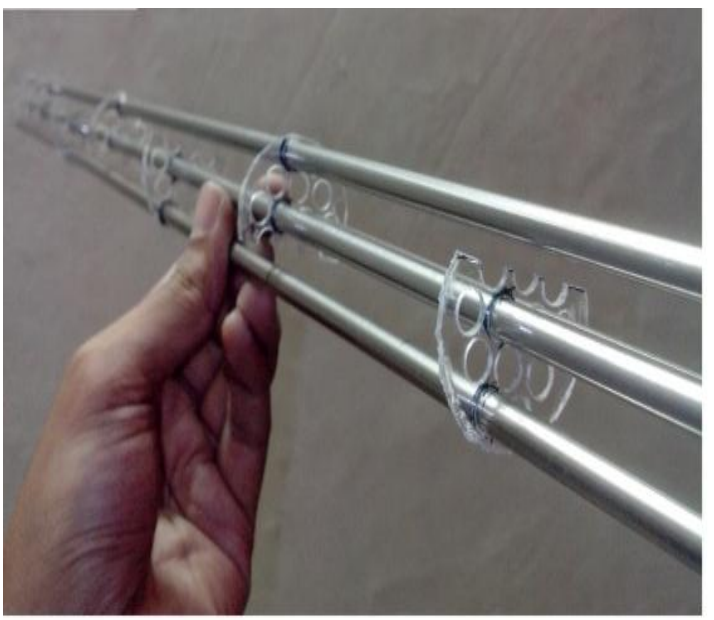

Figure-4

\subsection{Helical baffle}

Now from Stehlik et al we have a formulation of the empirical formulas and we used these empirical formulas for the analytical measurements of heat transfer coefficient.

The calculations are just as follows.

$$
\begin{aligned}
& \mathrm{Nu}_{\mathrm{s}}=0.62 \times\left(0.3+\sqrt{\mathrm{Nu}_{\text {lam }}^{2}+\mathrm{Nu}_{\text {turb }}^{2}}\right) \times \mathrm{Y}_{2} \times \mathrm{Y}_{3} \times \mathrm{Y}_{4} \times \mathrm{Y}_{7} \times \mathrm{Y}_{8} \times \mathrm{Y}_{9} \times \mathrm{Y}_{10} \\
& N u_{\text {lam }}=0.664 \mathrm{Re}^{0.5} \mathrm{Pr}^{0.33}=67.79
\end{aligned}
$$




$$
\begin{aligned}
& N u_{\text {turb }}=\frac{0.037 \operatorname{Re}^{0.7} \operatorname{Pr}}{1+2.433 \operatorname{Re}^{-0.1}\left(\operatorname{Pr}^{0.67}-1\right)}=20.179 \\
& Y_{2}=0.96 ; Y_{3}=1.0962 ; Y_{4}=1 ; Y_{7}=1.21 ; Y_{8}=0.32 Y_{9}=0.532 ; Y_{10}=0.483 ; h_{s}=512.365 \mathrm{~W} / \mathrm{m}^{2 \circ} \mathrm{C}
\end{aligned}
$$

Table 1 - Temperature Table for Helical Baffles

\begin{tabular}{|c|c|c|c|}
\hline Hot Fluid & Temp & Cold Fluid & Diff \\
\hline 74 & Higher Temp & 40 & 34 \\
\hline 50 & Lower Temp & 29 & 21 \\
\hline 24 & Differences & 11 & 13 \\
\hline
\end{tabular}

\subsection{COMPARISON BETWEEN THE PRESSURE DIFFERENCES}

After experiments were done on both the heat exchangers we have the values and they lead us to the conclusion that there is a $10.37 \%$ decrease in the pressure drop.

$$
\begin{aligned}
\text { Increase } \% & =\frac{\text { New Number }- \text { Original Number }}{\text { Original Number }} \times 100 \\
& =\frac{2598.76-2329.08}{2598.76} \times 100=10.37 \%
\end{aligned}
$$

\subsection{COMPARISON BETWEEN HEAT TRANSFER COEFFICIENT}

The analytical values of the Heat transfer coefficient has been seen as

$$
\frac{512.365-416.72}{416.72} \times 100=22.95 \%
$$

\subsection{COMPARISON BETWEEN LMTD}

The LMTD calculations we seen as

$$
\frac{26.98-25.04}{25.04} \times 100=7.74 \%
$$

\section{Conclusion}

From studying various journals we have found that the new Design of Helical Baffles as opposed to the conventional helical baffles has a better advantage in heat transfer and pressure drop. Hence both the type of heat exchangers were made. The helical Baffles were first designed in Solid works with a 50 to 60 deg angle and templates were made with 1:1 ratio. Same sizes of Shell and tube were used for both helical and Segmental Baffles. For Hot fluid we used water at $74^{\circ} \mathrm{C}$ and cold water at room temperature. Stainless steel tubes with ID 5.2 $\mathrm{mm}$ were used for tube and arranged in $60 \mathrm{deg}$ triangular pitch layout.

After the heat exchangers were assembled together experiments were conducted and from the experiments we conducted we see that the pressure drop was improved by $10.37 \%$. The heat transfer coefficient for helical baffles improved by 22.95\%.The Logarithmic Mean temperature Difference (LMTD) was improved by 7.74\%.From all this we make a strong conclusion that the helical baffles is a considerable upgrade to the existing heat exchangers and implementing helical baffles is suggested.

\section{References}

[1]. Master, B. I., Chunangad, K. S., and Pushpanathan, V., 2003, "Fouling MitigationUsing Helixchanger Heat Exchangers," Proceedings of the ECI Conferenceon Heat Exchanger Fouling and Cleaning: Fundamentals and Applications,Santa Fe, NM, May 18-22, pp. 317-322.

[2]. Bell, K. J., 1981, "Delaware Method for Shell Side Design," Heat ExchangersThermal Hydraulic Fundamentals and Design, S. Kakac, A. E. Bergles, and F.

[3]. Mayinger, eds., Taylor \& Francis, Washington, DC.

[4]. Bell, K. J., 1986, “Delaware Method of Shell Side Design,” Heat ExchangerSourcebook, J. W. Pallen, ed., Hemisphere, Washington, DC.

[5]. Bell, K. J., 1988, "Delaware Method of Shell-Side Design," Heat TransferEquipment Design, R. K. Shah, E. C. Sunnarao, and R. A. Mashelkar, eds.,Taylor \& Francis, New York.

[6]. Bell, K. J., 2004, "Heat Exchanger Design for the Process Industries,” ASME J. Heat Transfer, 126_6_, pp. 877-885.

[7]. Schlünder, E. U., ed., 1983, Heat Exchanger Design Handbook, Vol. 3, Hemisphere,Washington, DC.

[8]. Mukherjee, R., 1992, "Use Double-Segmental Baffles in the Shell-and-Tube

[9]. Heat Exchangers," Chem. Eng. Prog., 88, pp. 47-52.

[10]. Saffar-Avval, M., and Damangir, E., 1995, "A General Correlation for DeterminingOptimum Baffle Spacing for All Types of Shell and Tube Exchangers,"Int. J. Heat Mass Transfer, 38_13_, pp. 2501-2506.

[11]. Li, H. D., and Kottke, V., 1998, "Effect of Baffle Spacing on Pressure Dropand Local Heat Transfer in Shell-and-Tube Heat Exchangers for StaggeredTube Arrangement,” Int. J. Heat Mass Transfer, 41_10_, pp. 1303-1311. 
[12]. Stehlík, P., and Wadekar, V. V., 2002, "Different Strategies to Improve Industrial

[13]. Heat Exchange," Heat Transfer Eng., 23_6_, pp. 36-48.

[14]. Khalifeh Soltan, B., Saffar-Avval, M., and Damangir, E., 2004, "Minimizationof Capital and Operating Costs of Shell and Tube Condensers Using Optimum

[15]. Baffle Spacing,” Appl. Therm. Eng., 24_17-18_, pp. 2801-2810.

[16]. Lutcha, J., and Nemcansky, J., 1990, "Performance Improvement of TubularHeat Exchangers by Helical Baffles," Trans. Inst. Chem. Eng., Part A, 68, pp. 263-270.

[17]. Stehlik, P., Nemcansky, J., and Kral, D., 1994, "Comparison of CorrectionFactors for Shell-and-Tube Heat Exchangers With Segmental or Helical 